\title{
Evaluation of surgical treatment of rhinophyma with tangential shear of the lesion
}

\author{
Henryk Witmanowski ${ }^{1,2}$, Edward Lewandowicz ${ }^{3}$, Daria Sobieszek ${ }^{3}$, Magdalena Łuczkowska ${ }^{4}$, Jan Rykała ${ }^{3}$
}

1Department of Plastic, Reconstructive and Aesthetic Surgery, Nicolaus Copernicus University, Collegium Medicum, Bydgoszcz, Poland Head: Prof. Henryk Witmanowski MD, PhD

2Department of Physiology, Poznan University of Medical Sciences, Poland

Head: Prof. Teresa Torlińska MD, PhD

${ }^{3}$ Department of Plastic, Reconstructive and Aesthetic Surgery, Medical University of Lodz, Poland

Head: Prof. Bogusław Antoszewski MD, PhD

${ }^{4}$ Department of Dermatology, Poznan University of Medical Sciences, Poland

Head: Prof. Wojciech Silny MD, PhD

Postep Derm Alergol 2012; XXIX, 6: 411-416

DOI: $10.5114 /$ pdia.2012.32387

\begin{abstract}
Introduction: Tuberosity of the nose is a slow, progressive, gentle process, leading to distortion and dysfunction of the nose. Underlying the change is perifollicular hypertrophy of the sebaceous glands, fibrous tissue proliferation and vascular changes of telangiectasia type. It is believed that it is the final stage of rosacea.

Aim: To evaluate the effectiveness of surgical treatment using the method of tangential shear, based on a medical examination and subjective assessment of the effects of treatment by the patient.

Material and methods: In the years 1998 to 2008 nine patients with moderate degree of rhinophyma were treated surgically by tangential shear, followed by electrocoagulation. The results were assessed according to a 4-point scale as very good, good, fair and poor. We evaluated the presence of postoperative complications (bleeding, infection, or other), healing time, the shape of the nose (size and symmetry), improved patency, reduction in the number of inflammatory conditions, widening of the field of view and long-term effects of treatment: disfiguring scars, uneven surface of the nose, nasal deformity and recurrence.

Results: Among the 9 patients studied in 2 cases a very good result was achieved, in 5 good and in 2 satisfactory; no poor result was observed. Healing took an average of 6 weeks (1-15 weeks). None of the patients had postoperative complications. Seven patients were satisfied with both the size and symmetry of the nose, one unsatisfied with the size and 1 dissatisfied with the symmetry. Following the operation, 1 patient had disfiguring scars, 3 uneven surface of the nose, nasal deformity was observed in 2 cases and there was 1 recurrence. Of the 2 patients with a satisfactory result, 1 has been re-operated on, while the other was set an additional term of treatment.

Conclusions: Surgical treatment of nasal tuberosity by tangential shear followed by electrocoagulation is effective, and burdened by low rates of complications. To achieve a good aesthetic and functional effect, a very experienced operator is recommended.
\end{abstract}

Key words: rhinophyma, nasal tuberosity surgical treatment, rhinophyma treatment effects.

\section{Introduction}

\section{History}

The first mention of tuberosity of the nose appeared in the literature of Greek and Arabic already about 2000 BC [1]. The term rhinophyma (from the Greek rhis (nose) and phyma (growth)) was first used by Ferdinand Hebra in 1845 [2]. In the literature we find other terms for the dis- ease: "drunken nose, elephantiasis of the nose, hypertrophic or acne nose, potato like nose" [3].

\section{Etiology}

Although observed in isolation, tuberosity of the nose is considered to be the final stage of rosacea. Tuberosity of the nose is a slow, progressive, painless, gentle process, leading to distortion and dysfunction of the nose. The underlying change is perifollicular hypertrophy of the seba-

Address for correspondence: Prof. Henryk Witmanowski MD, PhD, Department of Plastic, Reconstructive and Aesthetic Surgery, Nicolaus Copernicus University, Collegium Medicum, 9 M. Skłodowskiej-Curie, 85-094 Bydgoszcz, Poland, phone: +48 5258540 17, e-mail: hewit7@wp.pl 
ceous glands, fibrous tissue proliferation and extension of the superficial vessels of the skin.

Histopathological evaluation is as in the case of elephantiasis. The histopathological examination reveals perifollicular chronic inflammation, perivascular inflammation of the skin, hair follicle hyperkeratosis, hyperplasia of collagen, and enlargement and swelling of the vessels of the skin, which increases blood flow [2, 4-6].

Likely involved in the etiology is human Demodex (D. folliculorum, detected in the hair follicles, and D. brevis, detected in sebaceous glands), which is believed to stimulate the inflammatory process [4]. The disease is more common in Caucasian men, mostly aged 40-60 years, who also get the condition more often than women. It often occurs in the countries of Western Europe, but is extremely rare in Japan [7]. Changes are most often located in the lower half of the nose, but are occasionally observed on the chin, the cheek or ear [7]. Deficiencies of vitamins, especially B group, hot spices, alcohol, and certain medications such as phenytoin $[8,9]$ can lead to tuberosity. Research by Curnier et al. contradicts the common belief that alcoholism contributes to the development of this disease. In their studies, they have not confirmed this relationship [10]. Predisposing factors are hormonal disorders, as evidenced by the frequent occurrence of rhinophyma in the peri-menopausal period and in women taking birth control pills (6.5), and disorders of the gastrointestinal tract. Mechanical squeezing of blackheads around the bridge of the nose may predispose to the formation of tuberosity.

The process of fibrosis, including related to an excess of tumor growth factor $\beta$ (TGF- $\beta$ ), has been observed in rhinophyma. There are three forms of TGF- $\beta$ : 1 and 2 , which stimulate fibrosis, and TGF- $\beta 3$, which inhibits this process. Payne et al. compared the levels of TGF- $\beta 1$, TGF- $\beta 2$ and TGF- $\beta 3$ in the skin of eight patients with rhinophyma and nine treated for some other reason, and found that the patients with rhinophyma have a greater concentration of cytokines TGF- $\beta 1$ and TGF- $\beta 2$ [11]. Increased levels of TGF- $\beta 2$ in patients with rhinophyma were also reported by Pu et al. [12]. Patients with rhinophyma were treated with tamoxifen, causing a reduction in the concentration of TGF- $\beta$ [13].

\section{Characteristics}

Fibrous and follicular form of tuberosity are distinguished with five levels of progression [14-16]:

I - slight expansion of blood vessels,

II - expansion of individual sebaceous glands,

III - nodular lesions in different parts of the nose,

IV - nodular changed skin and subcutaneous tissue, overgrown mesh of blood vessels, dilated sebaceous glands within the nose,

$\mathrm{V}$ - changes similar to those in stage IV but more advanced [17, 18].

Within the nodular lesions have been observed basalcell or squamous-cell carcinoma (BCC, SCC), and even sar- coma (angiosarcoma) [19-22], so it is recommended to perform histopathological examination, in each case of operated tuberosity [15]. There was also described a case of amyloidosis, a complication of rhinophyma [23]. Blepharitis, conjunctivitis, iritis, and corneal complications may be observed in the course of tuberosity [24]. Despite many studies, the etiology and pathogenesis still remain unclear.

\section{Treatment}

Functional disorders and aesthetic issues are the cause of presentation of patients. The method of choice is surgical treatment [25], consisting usually of tuberosity scalpel cutting or complete excision and covering the wound with a skin graft [26].

The recommended method is to cut with a knife followed by dermabrasion [27]. Bogetti et al. believe that the best method is a combination of cut and bipolar electrocoagulation and the local administration of epinephrine to reduce bleeding [28]. The use of gelatin-thrombin mixture may reduce bleeding [29]. Treatment with laser (argon, $\mathrm{Nd}$ :YAG and $\mathrm{CO}_{2}$ ) can be used in patients not eligible for conventional surgery. The advantages of laser therapy include short healing time $[9,30]$. Very good aesthetic results also were observed after using electrocautery, cryotherapy or dermatome Goulian's [31-33]. Attempts were made at conservative treatment such as tamoxifen, but surgery remains the treatment of choice [13, 34, 35] (Figures 1-3).

\section{Aim}

To evaluate the effectiveness of surgical treatment by tangential shear, based on a medical examination and subjective survey-based assessment of the long-term effects of treatment by the patient. The work is based on examples of patients who underwent surgical treatment at the Department of Plastic, Reconstructive and Aesthetic Surgery, Medical University of Lodz, because of tuberosity of the nose in the years 1998 to 2008.

\section{Material and methods}

In 1998-2008 the Department of Plastic Surgery treated 9 patients with rhinophyma with the tangential shear method followed by electrocoagulation. Age of patients ranged from 45 to 83 years. Patients volunteered for aesthetic reasons, in some cases also because of dysfunction. All patients were previously treated dermatologically due to rosacea. Before surgery, all patients were cured of any infections that may have complicated the operated nose, as well as other infections of the face and mouth. The procedure was performed under local anesthesia (lidocaine with noradrenaline). Patients scheduled for surgery underwent simple shear (decortication) with electrocoagulation of bleeding vessels, and post-operative wound compression dressing with ointment. 

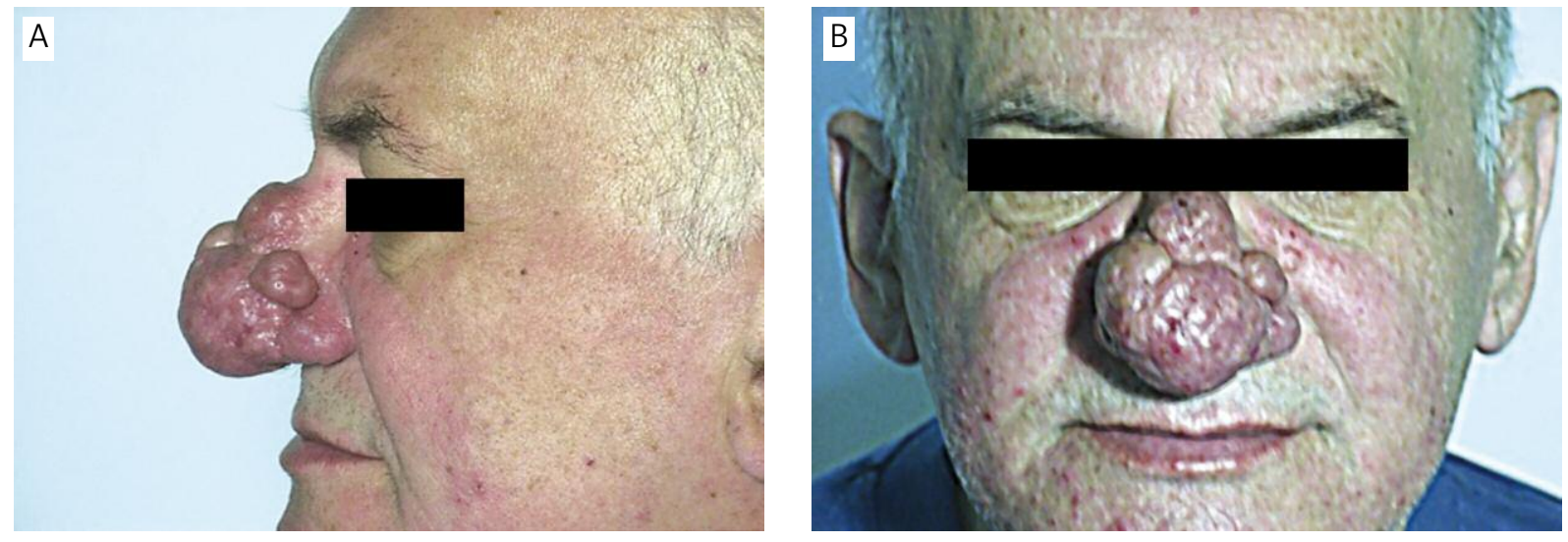

C
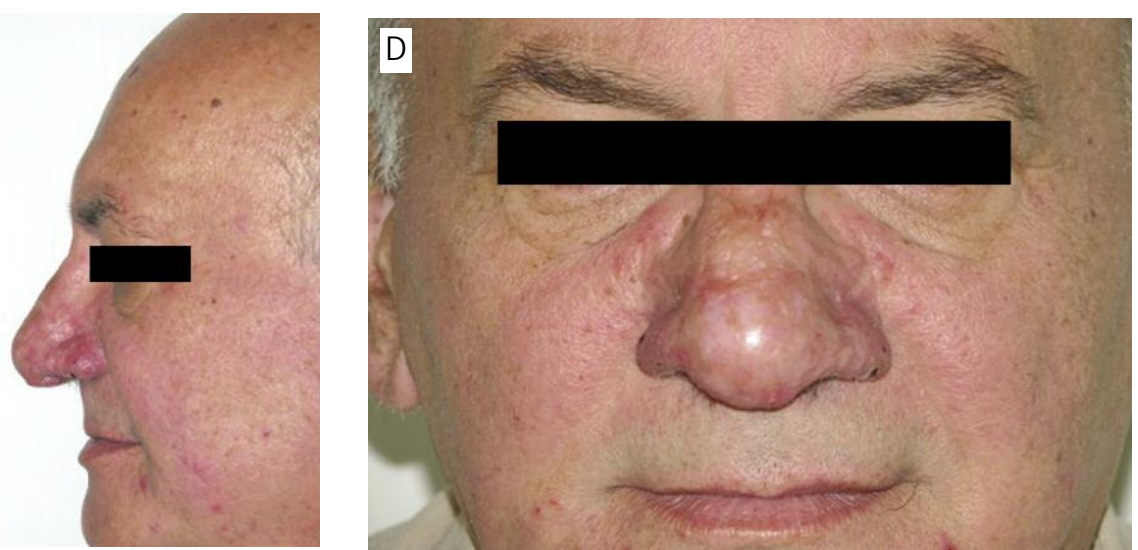

Figure 1. Patient 61 years old. Before (A, B) and after (C, D) surgery
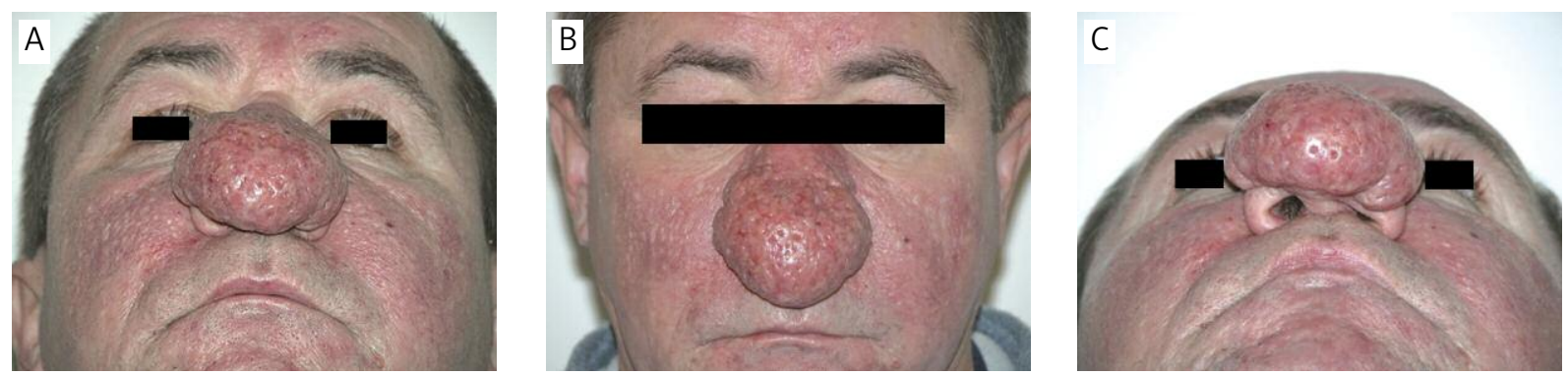

D
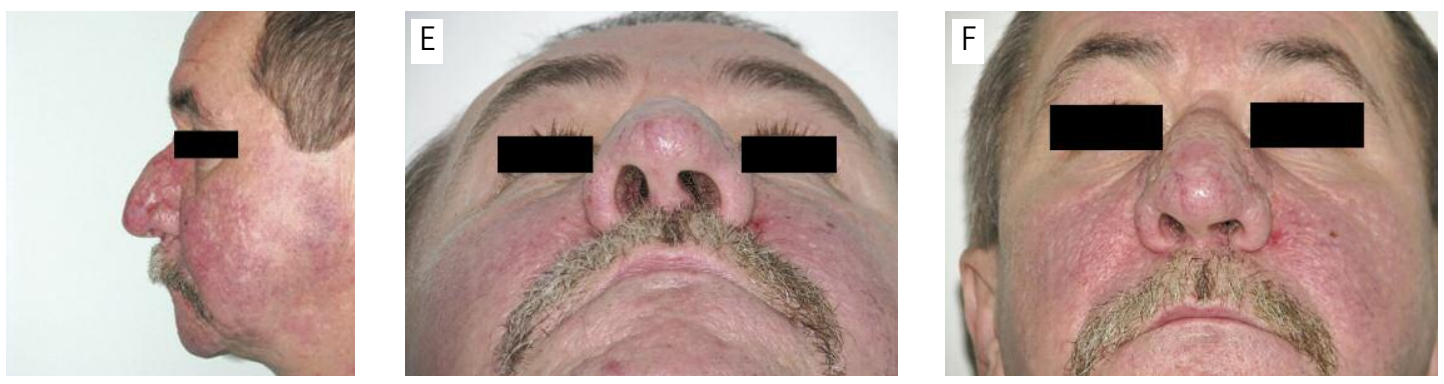

Figure 2. Patient 51 years old. Before (A-C) and after (D-F) surgery 

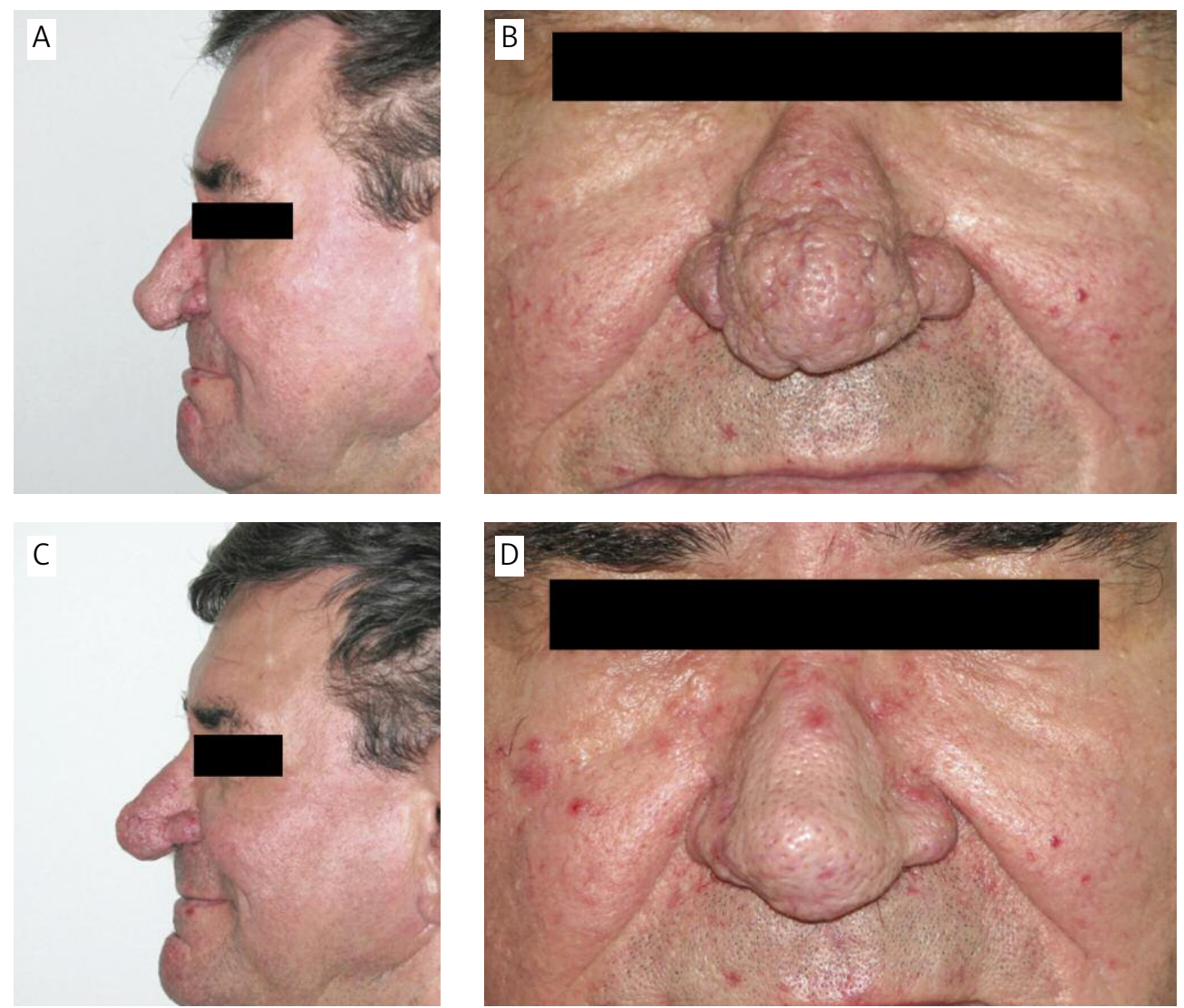

Figure 3. Patient 61 years old. Before (A, B) and after (C, D) treatment

\section{Results}

The results of surgery were evaluated on the basis of the medical examination and questionnaires filled out by them (at least 6 months after surgery). Taking into account the patients' subjective evaluation, the results were evaluated according to the four-level scale ratings:

- very good result - no visible signs of surgery, the patient is satisfied with the cosmetic effect,

Table 1. Evaluation of the results of treatment of rhinophyma based on surveys

\begin{tabular}{lccccc}
\hline Group of patients & \multicolumn{3}{c}{ Result } & Together \\
\cline { 2 - 5 } & Very good & Good & Satisfactory & Poor \\
\hline Tangential shear & $2(22 \%)$ & $5(56 \%)$ & $2(22 \%)$ & 0 & $9(100 \%)$ \\
\hline Postoperative complications & 0 & 0 & 0 & 0 & 0 \\
\hline
\end{tabular}

Table 2. Assessment of patient satisfaction with the shape of the nose on the basis of questionnaires

\begin{tabular}{|c|c|c|c|c|c|c|c|c|c|c|}
\hline Patients & & P.K. & S.J. & O.M. & K.A. & W.B. & W.K. & K.W. & B.P. & S.A. \\
\hline [years] & & 51 & 57 & 77 & 62 & 70 & 61 & 51 & 61 & 45 \\
\hline \multirow[t]{2}{*}{ Shape } & Volume & + & - & + & + & + & + & + & + & + \\
\hline & Symmetry & - & + & + & + & + & + & + & + & + \\
\hline
\end{tabular}

+Patient content, - patient unsatisfied 
- good result - slight traces of the operation, the patient is satisfied with the cosmetic effect,

- satisfactory result - visible scars or abnormal shape of the nose, the patient is satisfied,

- poor result - post-operative complications, poor cosmetic result, the patient is unsatisfied (Tables 1-3).

\section{Discussion}

Among the 9 patients studied 2 achieved a very good result, 5 good and 2 satisfactory, with no poor result. Healing took an average of 6 weeks (1-15 weeks). None of the patients had postoperative complications. Seven patients were satisfied with both the size and symmetry of the nose, one unhappy with the size and 1 dissatisfied with the symmetry. Following the operation, one patient had disfiguring scars, there were uneven surfaces in 3 patients, nasal deformity in 2 and in one recurrence. Of the 2 patients with a satisfactory result, 1 has been reoperated on, while the other was set an additional term of treatment.

Treatment of tuberosity of the nose is not causal treatment as the etiology of the disease remains unknown. The method of choice is surgery, consisting of the partial removal of the altered tissue, sparing skin appendages (hair follicles) that are later the focus of epithelialization. Recovery from the surgery usually takes about 2 weeks. Removal of the appendages can lead to distortions, difficult to correct, particularly in the wings and tip of the nose [36]. In treatment of major changes complete excision with application of intermediate or full thickness skin grafts is helpful. The results of the operation are sometimes unsatisfactory due to erythema, which makes the transplant look like a bright spot $[26,37]$. In treatment of tuberosity, cryosurgery, electrosurgery [29, 30, 38, 39], water knife [40, 41] or lasers [40, 41, 43] can be used. Gjuric and Rettinger compared laser therapy with electrosurgery. No significant difference was found; the only advantage of the laser was less bleeding during surgery and more comfortable postoperative course [33]. Simultaneous use of both methods simultaneously in the same patient on opposite sides of the nose in the initial phase of wound healing caused no significant differences after the treatment. After 1 year a slight scarring after electrosurgery was found, but other differences were not observed [45]. Laser treatment takes more time, is more complicated, requiring expensive equipment, greater outlay, and the treatment results are comparable with other methods [32]. Rex et al., using the method of laser and electroresection, observed similar efficacy of the two of them, at a much lower cost of electrocautery [46].

\section{Conclusions}

Based on our own observations, we believe that surgical treatment of nasal tuberosity by tangential shear fol-
Table 3. Assessment of long-term outcome based on surveys

\begin{tabular}{lcccc}
\hline $\begin{array}{l}\text { Patient } \\
\text { [years] }\end{array}$ & \multicolumn{5}{c}{ Long-term results } \\
\cline { 2 - 5 } & Scars & $\begin{array}{c}\text { Uneven } \\
\text { surface }\end{array}$ & Deformation & Recurrence \\
\hline P.K. 51 & + & - & - & - \\
\hline S.J. 57 & - & + & + & + \\
\hline O.M. 77 & - & - & - & - \\
\hline K.A. 62 & - & - & - & - \\
\hline W.B. 70 & - & + & - & - \\
\hline W.K. 61 & - & + & - & - \\
\hline K.W. 50 & - & - & - & - \\
\hline B.P. 61 & - & - & - & - \\
\hline S.A. 45 & - & - & + & \\
\hline
\end{tabular}

+Good long-term result, - poor long-term result

lowed by electrocoagulation is effective, and burdened by low rates of complications. High experience of the surgeon is necessary to obtain good aesthetic and functional results.

\section{References}

1. Lewandowicz E, Przewratil P, Bratoś R. Surgical treatment of nasal tuberosity. Przegl Dermatol 1995; 82: 304-8.

2. Hadeed HH, Sotereanos GC. Reconstructive rhinoplasty for rhinophyma. J Oral Maxillofac Surg 1991; 49: 308-9.

3. Beg MSA. Rhinophyma and its management. J Pak Assoc Dermatol 2001; 11: 56-7.

4. Sibenge S, Gawkrodger DJ. Rosacea: a study of clinical patterns, blood flow, and the role of Demodex folliculorum. J Am Acad Dermatol 1992; 26: 590-3.

5. Aloi F, Tomasini C, Soro E, Pippione M. The clinicopathologic spectrum of rhinophyma. J Am Acad Dermatol 2000; 42: 468-72.

6. Moulin G, Guilland V. Le rhinophyma. Ann Dermatol Venereol 1991; 118: 319-22.

7. Furukawa M, Kanetou K. Rhinophyma in Japan. Int J Dermatol 1994; 33: 35-7.

8. Jaramillo MJ, Kolhe PS. Phenytoin induced rhinophyma treated by excision and full thickness skin grafting. Br J Plast Surg 2000; 53: 521-3.

9. Calle SC, Nickerson R. Rhinophyma. Otolaryngol Head Neck Surg 1994; 110: 253-4.

10. Curnier A, Choudhary S. Rhinophyma: dispelling the myths. Plast Reconstr Surg 2004; 114: 351-4.

11. Payne WG, Wang X, Walusimbi M, et al. Further evidence for the role of fibrosis in the pathobiology of rhinophyma. Ann Plast Surg 2002; 48: 641-5.

12. Pu LLQ, Smith PD, Payne WG, et al. Overexpression of transforming growth factor beta-2 and its receptor in rhinophyma: an alternative mechanism of pathobiology. Ann Plast Surgy 2000; 45: 515-9.

13. Payne WG, Ko F, Anspaughs S, et al. Down-regulating causes of fibrosis with tamoxifen: a possible cellular/molecular approach to treat rhinophyma. Ann Plast Surg 2006; 56: 301-5. 
14. Mathur NN, Kumar S, Bothra R, et al. Fibrous variant of rhinophyma. Indian J Otolaryngol Head Neck Surg 2003; 55: 206-8.

15. Verna G, Raso M, Fava F, et al. Rhinophyma's fibrous variant: an immunohistochemical study with mib-1 antibody. Eur J Plast Surg 2001; 24: 114-7.

16. Gugic D, DeLair D, Vincek V. Unusual cystic variant of rhinophyma. Cutis 2007; 80: 484-6.

17. Frontczak M, Toborek K. Surgical treatment of nasal tuberosity (rhinophyma). Przegl Dermatol 1998; 85: 127.

18. Borzęcki A, Cielica W, Łoza K. Rhinophyma - $\mathrm{CO}_{2}$ laser treatment - own experiences. Nowa Medycyna 2003, 1.

19. Gallardo MA, Bosch RJ, Vidal L, et al. Angiosarcoma arising on rhinophyma. Eur J Dermatol 2000; 10: 555-8.

20. Leyngold M, Leyngold I, Letourneau PR, et al. Basalcell carcinoma and rhinophyma. Ann Plastic Surg 2008; 61: 410-2.

21. Aguila LI, Sanchez JL. Angiosarcoma of the face resembling rhinophyma. J Am Acad Dermatol 2003; 49: 530-1.

22. Lutz ME, Otley CC. Rhinophyma and coexisting occult skin cancers. Dermatol Surg 2001; 27: 201-2.

23. Nanda V, Garg K, Chittoria R, et al. Amyloidosis complicating rhinophyma. Aesth Plast Surg 2004; 28: 98-9.

24. Wyględowska-Kania M, Pierzchała E, Krauze E. Skuteczność chirurgicznego leczenia przerosłej postaci trądziku różowatego (rhinophyma). Dermatol Estet 2002; 5: 268.

25. Sadick H, Goepel B, Bersch C, et al. Rhinophyma: diagnosis and treatment options for a disfiguring tumor of the nose. Ann Plast Surg 2008; 61: 114-20.

26. Kose R, Okur M, Guldur ME. Giant rhinophyma in a bronchical asthma patient treated by excision and full thickness skin grafting. Dermatology Online J 2008; 14: 9.

27. Gupta S, Handa S, Saraswat A, Kumar B. Conventional cold excision combined with dermabrasion for rinophyma. J Dermatol 2000; 27: 116-20

28. Bogetti P, Boltri M, Spagnoli G, Dolcet M. Surgical treatment of rhinophyma: a comparison of techniques. Aesth Plast Surg 2002: 26: 57-60.

29. Kaushik V, Tahery J, Malik TH, Jones PH. New surgical adjuncts in the treatment of rhinophyma: the microdebrider and FloSeal. J Laryngol Otol 2003; 117: 551-2.

30. Orenstein A, Haik J, Tamir J. Treatment of rhinophyma with ER:YAG laser. Lasers in Surgery and Medicine 2001; 29: 230-5.

31. Goon PKY, Dalal M, Peart FC. The gold standard for decortication of rhinophyma: combined erbium - YAG $/ \mathrm{CO}_{2}$ laser. Aesth Plast Surg 2004; 28: 456-60.

32. Redett RJ, Manson PN, Goldberg N, et al. Methods and results of rhinophyma treatment. Plast Reconstr Surg 2001; 107: 1115-23.

33. Gjuric M, Rettinger G. Comparision of caron dioxide laser and electrosurgery in treatment of rhinophyma. Rhinology 1993; 31: 37-9.

34. Żaba R, Grzybowski G. Isotretinoin treatment of rosacea. Dermatol Estet 1999; 1: 106-11.

35. Lewandowicz E, Witmanowski H, Sobieszek D. Surgical treatment of rhinophyma. Postep Derm Alergol 2009; 26: 126-33.

36. Kilty S, Brownrig P. Surgical treatment of rhinophyma. J Otolaryngol Head Neck Surg 2008; 37: 269-72.

37. Kwanck O, Acarturk S. Ultrastructural and surface area changes of acute and traditional expanded full thickness skin grafs. Br J Plast Surg 1992; 45: 239-45.

38. Humzah MD, Pandya AN. A modified electroshave technique for the treatment of rhinophyma. Br J Plast Surg 2001; 54: 322-5.

39. Haar LG, Shabshay SM. Treatment of rhinophyma. Cold vs. laser technique. Arch Otolaryngol Head Neck Surg 1993; 119: 628-31.
40. Taghizadeh R, Mackay SP, Gilbert PM. Treatment of rhinophyma with the Versajet TM Hydrosurgery System. J Plast Reconstr Aesth Surgery 2008; 61: 330-3.

41. Nicolas J, Garmi R, Labbe D, et al. Interest of Versajet $\left({ }^{\circledR}\right)$ in surgical treatment of the rhinophyma. Case report. Ann Chir Plast Esthet 2009; 54: 78-81

42. Krupashankar DS. IADVL Dermatosurgery Task Force. Standard guidelines of care: $\mathrm{CO}_{2}$ laser for removal of benign skin lesions and resurfacing. Indian I Dermatol Venerol Leprol 2008; 74: 61-7.

43. Stucker FJ, Lian T, Sanders K. The ABCs of rhinophyma management. Am J Rhinol 2003; 17: 45-9.

44. Goepel B, Bersch C, Goessler U, Hoermann K. Rhinophyma: diagnosis and treatment options for a disfiguring tumor of the nose. Ann Plast Surg 2008; 61: 114-20.

45. Lloyd KM. Surgical correction of rhinophyma. Arch Dermatol 1990; 126: 721-2.

46. Rex J, Ribera M, Bielsa I, et al. Surgical management of rhinophyma: report of eight patients treated with electrosection. Dermatol Surg 2002; 28: 347-9. 